\title{
Caudal clonidine for pain relief in children undergoing sub- umbilical surgery: a randomized prospective trial
}

Hedi Chaker University Hospital , Sfax - Tunisia .

\section{Introduction}

In pediatric patients, caudal epidural is commonly used to provide better intra-operative and post-operative analgesia for sub-umbilical surgeries. Prolonging the duration of sensory blockade is the main interest of pediatric anesthesiologists. The aim of our study was to assess of the efficacy of the association of clonidine and fentanyl in prolonging the action of bupivacaine $0.25 \%$ when used for caudal epidural analgesia in children undergoing sub-umbilical surgeries.

\section{Material and methods}

After obtaining the Hedi Chaker university hospital (Tunisia) ethics committee approval and informed written consent from parents, 80 ASA I class patients aged from 1 to 5 years, scheduled for sub-umblical surgical procedures were enrolled in this prospective randomized double blinded controlled trial.

General anesthesia was standarizerd in both groups. The caudal injection was done by preprepared $20 \mathrm{ml}$ syringes labeled "study".

We injected $1 \mathrm{ml} / \mathrm{kg}$ of this pre-prepared solution caudally for each patient enrolled in this study. Patient was turned supine after administration of the drug. The anesthetist and nurses in-charge of the patient were completely blinded to the content of syringes.

Patients were randomized into 2 groups

Group I : received bupivacaine $2.5 \mathrm{mg} / \mathrm{kg}$ with fentanyl $1 \mu \mathrm{g} / \mathrm{kg}$ and clonidine $1 \mu \mathrm{g} / \mathrm{kg}$

Group II received bupivacaine $2.5 \mathrm{mg} / \mathrm{kg}$ with fentanyl $1 \mu \mathrm{g} / \mathrm{kg}$.

An increase of HR or MAP more than $20 \%$ comparing to baseline values, $15 \mathrm{~min}$ after administration of caudal anesthesia was considered as failure of caudal anesthesia and in this case, an intravenous dose of Alfentanyl $(20 \mu \mathrm{g} / \mathrm{Kg})$ was administrated. Patients, in whom caudal anesthesia failed, were excluded from the study

Pain was assessed by using CHEOPS Score [9] at the admission in the PACU $(\mathrm{H} 0)$, at the first $(\mathrm{H} 1)$, the second $(\mathrm{H} 2)$, the fourth $(\mathrm{H} 4)$, the sixth $(\mathrm{H} 6)$, the $12^{\text {th }}(\mathrm{H} 12)$ and the $24^{\text {th }}(\mathrm{H} 24)$ post operative hours. CHEOPS at $\mathrm{H} 12$ and $\mathrm{H} 24$ was assessed by phone because patients leaved the PACU at $\mathrm{H} 6$ as it was a day case surgical procedure. In the PACU, if patients had CHEOPS superior to 7, or if they requested, an additional analgesia was given
After the exit of PACU, all patients received $15 \mathrm{mg} / \mathrm{kg}$ of paracetamol orally 4 times a day. Oral ibuprofen was prescribed for analgesia after discharge. Children received $5 \mathrm{mg} \mathrm{kg}-1$ of ibuprofen for pain scores of 7or greater on CHEOPS.

\section{Results}

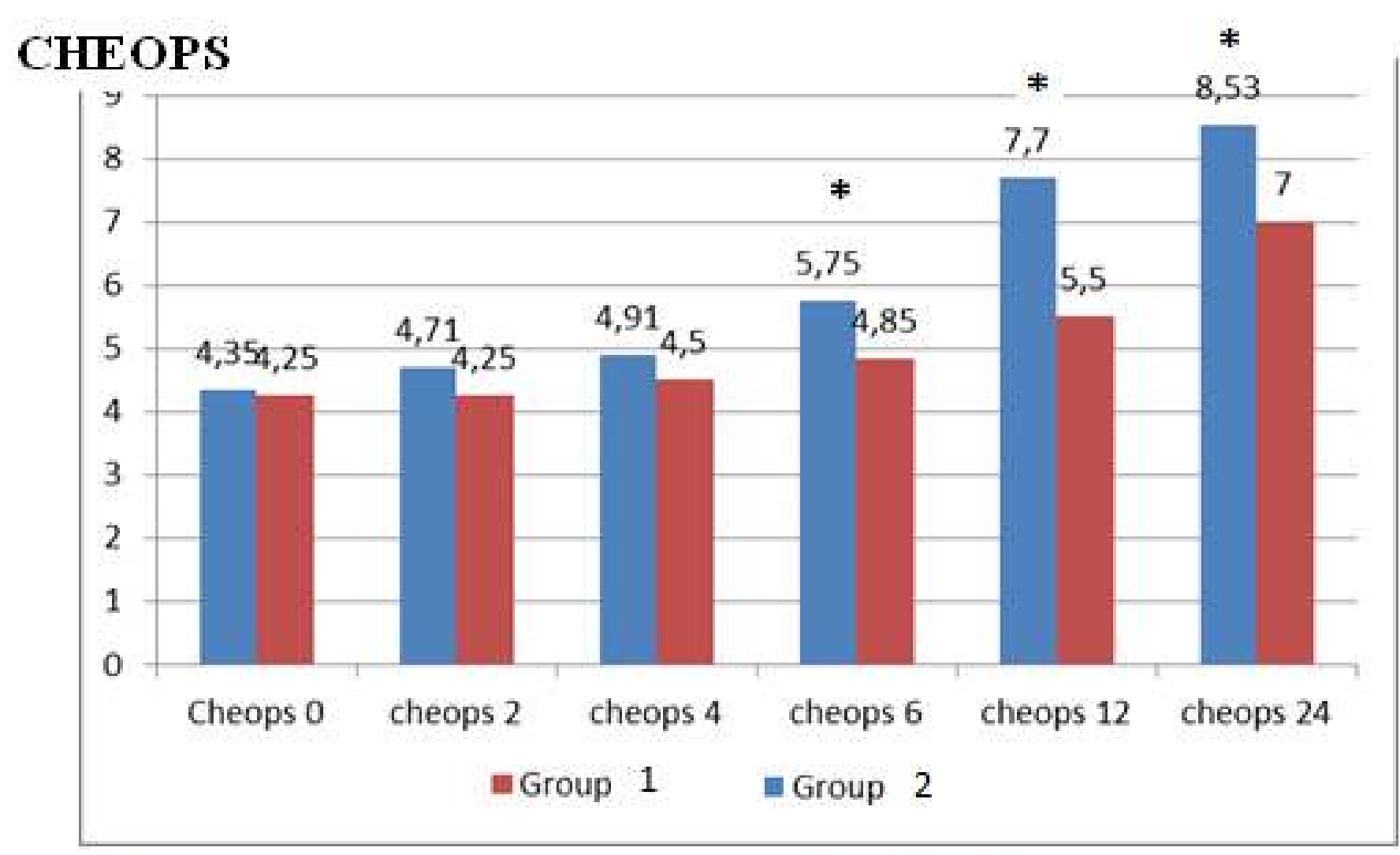

Figure 1: post operative pain assessed by CHEOPS.

\begin{tabular}{|l|l|l|l|}
\hline & $\begin{array}{l}\text { Group I } \\
\mathrm{N}=40\end{array}$ & $\begin{array}{l}\text { Group II } \\
\mathrm{N}=40\end{array}$ & $\mathrm{p}$ \\
\hline Nausea and vomiting & 3 & 2 & - \\
\hline Respiratory depression & 0 & 0 & - \\
\hline bradycardia & 0 & 0 & - \\
\hline Pruritus & 0 & 1 & - \\
\hline Motor residual blockade & 4 & 12 & 0.044 \\
\hline
\end{tabular}

Incidence of side effects: number of patients having side effects

Discussion : our results are in concordance with the previopus studies of litterature. The high rates of motor blockade may be explained by the use of bupivacaine in place of ropivacaine.

\section{Conclusion :}

The addition of clonidine and fentanyl to bupivacaine prolongs the duration of analgesia after single shot caudal epidural anesthesia at the cost of increased side effects like motor blockade

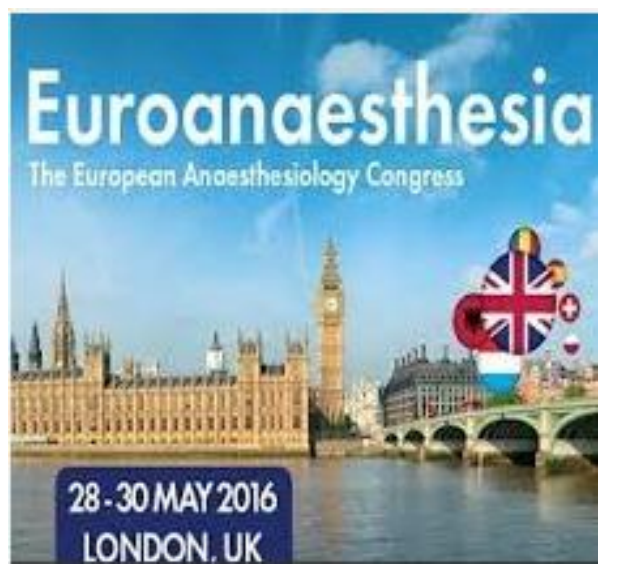

